\title{
BRENTANO’S CONCEPT OF Mind \\ Underlying Nature, Reference-Fixing, and the Mark of the Mental
}

\author{
Uriah Kriegel
}

Forthcoming in S. Lapointe and C. Pincock (eds.), Innovations in the History of Analytical Philosophy (Palgrave)

\section{Introduction/Abstract}

Perhaps the philosophical thesis most commonly associated with Brentano is that intentionality is the mark of the mental. But in fact Brentano often and centrally uses also what he calls 'inner perception' to demarcate the mental. In this chapter, I offer a new interpretation of Brentano's conception of the interrelations among mentality, intentionality, and inner perception. According to this interpretation, Brentano took the concept of mind to be a natural-kind concept, with intentionality constituting the underlying nature of the mental and inner-perceivability serving as the concept's reference-fixer.

\section{Intentionality as the Mark of the Mental: Problems with the Orthodox Interpretation}

Brentano's (1874) Psychology from an Empirical Standpoint is an attempt to provide systematic conceptual and methodological foundations for the scientific study of mind. The first order of business for such an exercise is to offer a sound and principled demarcation of the relevant domain of phenomena. Brentano addresses this task in the first chapter of Book II of the Psychology. 
It is commonly said that Brentano demarcated the mental domain by appeal to the phenomenon of intentionality, an event's or state's directedness toward something other than itself. ${ }^{1}$ Intentionality is thus the 'mark of the mental.' The thesis can be stated as follows:

(M3) All and only mental phenomena are intentional phenomena.

If this is true, then indeed we have a workable way of separating mental from nonmental phenomena.

There are two problems with this interpretation, however. The first and most obvious is that in the chapter of the Psychology dedicated to the demarcation issue, Brentano endorses no fewer than six ways of drawing the mental/physical distinction. Intentionality is only one of them - the third he considers. In what sense, then, is intentionality the mark (rather than just $a$ mark) of the mental? The others include:

(M1) All and only mental phenomena are either presentations or based on presentations. $^{2}$

(M2) All and only mental phenomena are not spatially extended. ${ }^{3}$

(M4) All and only mental phenomena are objects of inner perception. ${ }^{4}$

(M4')All and only mental phenomena are objects of perception in the success sense of the term (Wahrnehmung). ${ }^{5}$

(M5) All and only mental phenomena are not only phenomenally but also noumenally real (they are not only appearances but also realities). ${ }^{6}$

(M6) All and only mental phenomena necessarily appear to us as unities. ${ }^{7}$

I will discuss some of these more fully in §3. For now, what is important to note is that intentionality is neither the first nor the last of the marks discussed by Brentano, and he does not discuss it at any special length. ${ }^{8}$

At the same time, in summarizing the discussion toward the end of the chapter, Brentano does write that 'The feature/characteristic/mark (Merkmal) which best characterizes (meisten kennzeichnet) mental phenomena is undoubtedly 
their intentional inexistence' (1874: 98 [I, 137]; my emphasis). Unfortunately, he says nothing about what makes it best, and in what sense.

The second problem with the orthodox interpretation comes from the very opening chapter of the Psychology. This chapter has two goals: to fix on the topic of investigation and to explain why it is important to investigate. Interestingly, the first of these goals effectively involves a kind of initial demarcation of the subject matter, insofar as it requires a basic conception of what is being talked about. The problem is that nowhere in this chapter is intentionality mentioned, and instead one of the other marks later discussed, the inner-perceivability cited in M4, is operative. The same happens in Brentano's presentation of his subject matter in Descriptive Psychology (based on lectures from circa 1890), whose very first sentence reads: 'Psychology is the science of people's inner life, that is, the part of life which is captured in inner perception' (1982: 3 [1]). The recurrence of inner perception as a mark of the mental both at the outset of inquiry and in the context of the more systematic search for a principled demarcation makes inner perception stand out among Brentano's six marks. If any of these six should be referred to as the mark of the mental should it not be inner-perceivability?

All this leaves us with a cluster of question marks. What does Brentano mean in saying that intentionality is the best of his proposed marks of the mental? If a mark thesis does the job of getting right the extension of the mental, what else can we expect from it? What other dimensions are we supposed to evaluate it along (and why)? Whatever further dimensions of evaluation there are, does intentionality really fare better along them than inner-perceivability? If it does, why is innerperceivability appealed to at the outset of inquiry? More generally, what makes inner-perceivability uniquely fit to define the subject matter at the outset? And why does it not retain its special status, but cedes it to intentionality, when the issue of demarcation becomes central (is 'thematized')? What in general is the relation between intentionality and inner-perceivability in Brentano's picture of the nature of mind? Are we sure Brentano has a stable view of all this? 
My goal in this chapter is to present an interpretation of Brentano's view that answers these questions. I will try to show that Brentano's view is not only stable but also quite plausible. In $\S 2$, I lay out my interpretation without argument. In §§34, I make a case for the interpretation's assignment of theoretical roles to intentionality and inner-perceivability (respectively).

\section{The Concept of Mind: Reference-Fixing and Underlying Nature}

The tension between intentionality and inner-perceivability as potential signatures of the mental is arguably a manifestation of a deeper tension that is something of a recurring theme in the philosophy of mind. This is the tension between metaphysical and epistemological ways of conceiving of the mental domain. There are good reasons to adopt each of these approaches.

Traditional metaphysics has tended to work with a conceptual division between three putative ontological spheres: physical, mental, and abstract. ${ }^{9}$ But it has often been suspected that what underlies this tripartite division are in truth three different ways of knowing (or acquiring knowledge of) the world: perception, introspection, and reason. Perception is our way of coming to know (or at least establish epistemic contact with) the domain of physical phenomena; introspection is our way of coming to know mental phenomena; and reason is our way of coming to know the realm of abstracta. ${ }^{10}$ It is not implausible that the way we get our initial handle on the mental as an independent domain of phenomena is by noting that there are certain phenomena of which we have a distinctive kind of knowledge introspective knowledge. We may later countenance non-introspectible mental states, but originally what anchors our conception of the mental is something like introspective encounter with certain phenomena.

At the same time, it is natural to expect there to be metaphysical homogeneity among the phenomena themselves - something in their nature that makes them belong together. The category of the mental is plausibly a natural kind. 
If so, there should be some feature common and peculiar to mental phenomena regardless of how we come to know them - something intrinsic to them that is distinctive of them and shared by all of them.

I contend that the tension between the epistemological and metaphysical ways of homing in on the mental is close to the surface in Brentano's text. On the one hand, he is tempted by the notion that we get our initial handle on the mental epistemologically, through the notion that all and only mental phenomena are objects of inner perception. On the other hand, he finds intentionality to be a deep feature common and peculiar to mental phenomena regardless of our knowledge of them.

I suggest that we can do justice to all these interpretive pressures by supposing that Brentano had something like the following picture in mind. Mental phenomena form a natural kind or 'real category.' Accordingly, the concept of mentality is a natural-kind concept. As such, we have to distinguish two aspects of its semantic character: a reference and a reference-fixing description (Kripke 1972). The reference is constituted by an underlying nature of the mental, which need not be transparent to us at the beginning of inquiry. By contrast, the reference-fixer is given by some description which gives us a pre-theoretic handle on what we aim to speak of, hence is transparent from the outset of inquiry. Although Brentano does not explicitly articulate this kind of broadly Kripkean framework, as we will see what he does say can be stabilized - brought into reflective equilibrium - by ascribing to him something like it.

On this view, the concept MIND, or MENTAL, works on the same model as other natural-kind concepts, such as WATER and HORSE. On the one hand, WATER refers to $\mathrm{H}_{2} \mathrm{O}$, the underlying nature common and peculiar to bodies of water. This means that anything composed of $\mathrm{H}_{2} \mathrm{O}$ molecules falls in the extension of WATER. On the other hand, the way we get our initial handle on what we are talking about is through a reference-fixing description such as 'the clear and drinkable liquid of our (perceptual) acquaintance.' The way the concept gets its reference is through this 
reference-fixer: some stuff satisfies the description 'the clear drinkable...,' and since the underlying nature of that description-satisfying stuff is $\mathrm{H}_{2} \mathrm{O}$, the concept's reference is $\mathrm{H}_{2} \mathrm{O}$. In other words, the concept of water is the concept of stuff that has the same underlying nature as the clear drinkable liquid of our perceptual acquaintance. Likewise, the reference of HORSE is given by anything with equine DNA (say) and is fixed by some such description as 'the tall rideable mammal of our perceptual acquaintance.' Some items in the world satisfy that description, and since their underlying nature is the equine DNA, anything with that DNA falls in the extension of HORSE. To that extent, the concept of horse is the concept of something that has the same underlying nature as the tall rideable mammals of our perceptual acquaintance.

For the concept MIND to work in the same way, there would have to be a reference-fixer and an underlying nature associated with it. The Brentanian thought, as I understand it, is that the underlying nature of mentality is intentionality, while the reference-fixing description is something like 'the phenomena of our innerperceptual acquaintance.' (The description is so general because the concept is. The same level of generality would attach to the concept PHYSICAL, where the referencefixing description would be something like 'the phenomena of our outer-perceptual acquaintance.') Thus some phenomena we encounter through inner perception, and the underlying nature of these phenomena happens to be their intentionality. Anything that exhibits intentionality therefore falls in the extension of MENTAL, even though initially our grasp of the category is anchored in inner perception. To that extent, the concept of the mental is the concept of something that has the same underlying nature as the phenomena of our inner-perceptual acquaintance.

To make the case for this interpretation of Brentano, I start (§3) with textual evidence for the idea that Brentano takes the concept of the mental to be something like a natural-kind concept, and takes intentionality to be something like the underlying nature of that kind. I then ( $\$ 4)$ turn to explain what Brentano means by 'inner perception' and show that he takes it to play the reference-fixing role. 


\section{Intentionality as the Underlying Nature of Mentality}

There is no question that Brentano believes in natural kinds, or categories, with essential natures. At several junctures in the Psychology, he warns against entanglement in terminological disputes and reminds the reader that the goal is to discern the natural joints in the domain of phenomena under consideration:

Disputes about what concept a term applies to are not always useless quarrels over words. Sometimes it is a question of establishing the conventional meaning of a word, from which it is always dangerous to deviate. Frequently, however, the problem is to discover the natural (naturgemäße) boundaries of a homogeneous class. (1874: 101 [I, 141])

In other words, there are two valuable types of exercise in this area. One is to collectively stipulate the meaning of a term, through convention, to smooth the conduct of inquiry. The other is to detect 'natural' relations of similarity and dissimilarity among the phenomena investigated and attach a term to the concept that picks them out. The picture is of a world of items or phenomena some of which naturally belong with others and not with yet others. It is clear that Brentano thinks of this 'belonging together' as in the nature of things, in the sense of being objective and observer-independent:

... scientific study must have classification and order, and these may not be arbitrary. They ought, as far as possible, to be natural (natürlich), and they are natural when they correspond to a classification of their subject-matter which is as natural (natürlichen) as possible. (1874: 177 [II, 1])

Similarity and dissimilarity relations hold independently of our classificatory activities, and the goal of those activities is to capture these relations (Compare Sider 2011).

Presumably, when some items belong together, this is because there is a feature common and peculiar to them - a kind of 'natural unifier' they share that marks them off from the rest of reality. We may say that for Brentano such items make up a natural kind, and the feature in virtue of which they do is their (or the 
kind's) underlying nature. What I want to suggest is that for Brentano, mentality is a natural kind and intentionality is its underlying nature.

To say that Brentano takes MENTAL to be a natural-kind concept is not to say that he associated with it all the features Kripke associated with natural-kind concepts. Brentano says nothing suggesting that the concept is a rigid designator, for example. But what I want to claim is that he does take the concept to pick out a category of phenomena that are naturally unified, and in ways that need not be accessible from the armchair. That is, it picks out a natural category with a hidden essence.

\subsection{Marks of the Mental and the Classification of Mental Phenomena}

As noted, Brentano identified several potential marks of the mental, though he also declared the third - intentionality - 'most characteristic' of the mental. What makes it better than others?

One thing that makes it better than some other candidates is straightforward: it is non-disjunctive and positive. The first mark Brentano considers, M1, is that of being either a presentation or based on a presentation. Brentano is dissatisfied with it because it is disjunctive: 'This... is not completely unified because it separates mental phenomena into two groups' (1874: 85 [I, 120]). (One might frame M1 in a less overtly disjunctive manner, say as the thesis that all and only mental states involve a presentation component; but presumably Brentano would retort that this does not unify the phenomena themselves, only their description.) The second mark, M2, is that all and only mental states lack spatial extension. Brentano is dissatisfied with this one chiefly because it is negative (and also because it is controversial, sociologically speaking):

... another definition common to all mental phenomena is still desirable. Whether certain mental and physical phenomena appear extended or not, the controversy proves that the criterion given for a clearer separation is not adequate. Furthermore, this criterion is only a negative definition of mental phenomena. (1874: 87-8 [I, 124]) 
This leads him to intentionality, which is satisfyingly positive and non-disjunctive. Still, the following three marks he discusses - inner-perceivability, noumenal reality, and special unity - are neither disjunctive nor negative. What makes intentionality nonetheless the deeper mark of the mental?

The answer to this, I contend, is effectively provided by the last chapters of Psychology II. The task of Chapters 5-8 is to provide an accurate classification of mental phenomena into 'fundamental classes.' The idea is that the mental domain is structured by genus/species relations, with mentality per se being the highest mental genus. This genus divides into some species, which divide in turn into subspecies, which divide into sub-sub-species, and so on. For Brentano, these genus/species relations are objective and observer-independent, so the task is to discover rather than invent them. Now, Brentano calls the second-to-highest mental genera (the immediate species of mentality) the 'fundamental classes' of mentality. His task in these chapters is thus to identify the second layer of mental genera. Crucially, the division or 'speciation' he ends up with appeals to intentionality, and does not appeal to inner-perceivability, noumenal reality, or special unity. As we will see momentarily, his different fundamental species of mentality differ in exhibiting different species of intentionality. We may therefore surmise that, for Brentano, intentionality is 'deeper' than other positive and non-disjunctive marks of the mental in providing not only a demarcation of the domain but also the domain's principle of speciation.

One fundamental class of mentality is what Brentano calls judgment. It covers any mental state concerned with what is the case, what is true, what exists, what obtains: 'By "judgment" we mean, in accordance with common philosophical usage, acceptance (as true) or rejection (as false)' (1874: 198 [II, 34]). The paradigmatic case here is belief, but the genus also includes perception, since perception presents what it does as obtaining or real: 'all perceptions are judgments, whether they are instances of knowledge of just mistaken affirmations' (1874: 209 [II, 50]). A visual perception of a laptop on a desk is committed, so to speak, to the laptop really being on the desk - to it being the case that there is a laptop on a desk. (We can call this 
kind of commitment 'doxastic commitment.') The distinguishing characteristic of states in this class - states of judgment - is that their 'formal object' is the true; their 'mode of intentionality,' as Brentano puts it, is directedness at the true.

This contrasts with states of the second fundamental class of mentality, which Brentano calls 'interest' or 'phenomena of love and hate.' These are states whose formal object is the good rather than the true:

If something can become the content of a judgment in that it can be accepted as true or rejected as false, it can also become the object of a phenomenon belonging to this [second] basic class, in that it can be agreeable (genehm) (in the broadest sense of the word) as something good, or disagreeable (ungenehm) as something bad. Here we are concerned with the object's value or lack thereof, whereas in the other case we were concerned with its truth or falsity. (1874: 239 [II, 88-9])

This class, too, covers a large group of phenomena, including emotion, affect, the will, and pain/pleasure. For this reason, Brentano has no satisfactory name for this class, and calls it alternately interest, emotion, or (often) 'phenomena of love and hate.' What unifies the phenomena in this category is the fact that they present what they do as good or bad. They present not what is the case but what should be the case, not what obtains but what ought to obtain. Wanting a beer presents beer as good, but so does taking pleasure in the beer, wishing for beer, liking beer, deciding on beer, and so on. All these states are committed, in different ways, to the goodness of beer. ${ }^{11}$ (We can call this 'axiological commitment.')

Brentano's third fundamental class is what he calls 'presentation' (Vorstellung). This is supposed to be an intentional state that in itself presents what it does neither as true nor as good, but in an entirely neutral, doxastically and axiologically noncommittal manner. In that respect, the most general characterization of presentation is this: 'We speak of a presentation whenever something appears (erscheint) to us' (Brentano 1874: 198 [II, 34]). Paradigmatic examples include imagery, as when one visualizes a smiling octopus, and states of entertaining or contemplating a proposition, such as that the hard problem of consciousness will be solved in the present millennium. Such states are in 
themselves 'intentionally neutral' precisely in presenting what they do neither as true nor as good. ${ }^{12}$

Brentano's classification divides mental phenomena, then, according to their 'mode of intentionality,' the manner in which they present their objects. This intentional classification of mental phenomena is so important to Brentano as to override what has been a central line of distinction in psychological classification since Aristotle, namely, the line between sensory/lower states and intellectual/higher states. Traditionally, the line between sensory perception and conceptual thought has been absolutely fundamental, as has been that between algedonic sensations (pain and pleasure) and more articulated exercises of the will (intention, aspiration, and so forth). Brentano recognizes this distinction, of course, but takes it to be less fundamental than the judgment-interest-presentation distinction. The reason for this, it would appear, is that he takes intentionality to generate the most fundamental speciation of the mental, and on his view the sensory and the intellectual are intentionally alike insofar as they share a formal object.

My contention is that this crucial role of intentionality in capturing the objective structure of the mental domain is what makes it a 'deeper' mark of the mental than inner-perceivability, noumenal reality, and special unity. It is what makes it not only a natural unifier of the mental domain but something like the underlying nature of mentality. It is a general feature of essential properties of a genus that they are not only coextensive with the genus but also provide its principle of speciation. All and only birds are feathered bipeds, but different species of birds are not distinguished by their different feathers. Meanwhile, all and only birds have avian DNA, and different species of birds are distinguished by their DNA, which is why avian DNA is a plausible candidate for an underlying nature of birdness. 
Brentano seems to recognize the basic connection between intentionality's 'depth' as demarcation of the mental domain and its role in providing the domain's principle of speciation. It is all but explicit in the following passage:

Nothing distinguishes mental phenomena from physical phenomena more than the fact that something is immanent [read: intentionally inexistent] as an object in them. For this reason (darum) it is easy to understand that the fundamental differences in the way something [in] exists in them as an object constitute the principal class differences among mental phenomena. (1874: 197 [II, 32])

I conclude that it is plausible to ascribe to Brentano the view that intentionality is the underlying nature of mentality - even though there are five other features equally extensionally adequate for demarcating the mental.

\subsection{Objections and Replies}

It might be objected that intentionality cannot be described, in Brentano's system, as anything like a Kripkean underlying nature, because it is a 'surface feature' rather than a 'hidden essence.' After all, for Brentano both intentionality itself and the differences among the three fundamental species of it are available to ordinary (inner) perception. In that respect, it is very different from such underlying natures as $\mathrm{H}_{2} \mathrm{O}$ and equine DNA.

In response, it should be conceded that some disanalogies with paradigmatic Kripkean hidden essences exist here. At the same time, there are also real similarities. Crucially, for Brentano one cannot establish a priori - 'from the armchair' - what the principle of speciation of the mental is, hence what its deepest mark is. As in the case of water and horses, empirical inquiry is needed:

A scientific classification... must be natural, that is to say, it must unite into a single class objects closely related by nature, and it must separate into different classes objects which are relatively distant by nature. Thus classification is only possible when there is a certain amount of knowledge of the objects to be classified, and it is the fundamental rule of classification that it should proceed from a study of the objects to be classified and not from a priori construction. (1874: 194 [II, 28]) 
This is certainly a symptom of an essence being 'hidden' - that one cannot establish its essentiality from the armchair. ${ }^{13}$

Another objection might be that there is a simpler explanation of what makes intentionality best among Brentano's marks of the mental. This is that all other marks appeal to overtly mental notions, such as presentation, perception, and appearance. They therefore cannot be used to reveal the essence of the mental in nonmental terms. By contrast, intentionality is not by definition a mental notion, and yet it proves perfectly coextensive with the mental.

My response is threefold. First, it is noteworthy that at no place does Brentano himself complain about the other marks that they presuppose mental notions. By contrast, as we just saw he does explicitly stress the connection between intentionality's special status and its role in speciating the mental. Secondly, it is not clear that all other marks presuppose mental notions. Certainly the second (nonspatiality) does not, and the fifth (noumenal reality) seems innocent as well. Thirdly, even if the intentional mark were special only because it did not presuppose mental notions, this would not necessarily undermine its status as an underlying nature of the mental. As the only feature both not ostensibly mental and coextensive with mentality, it might still serve as an underlying nature of the mental.

A completely different kind of concern might be that Brentano's view, as described here, is too implausible to be of interest. What makes it so implausible is that intentionality is both too broad and too narrow to demarcate mentality. It is too broad insofar as linguistic expressions, paintings, and traffic signs are all intentional yet nonmental. It is too narrow insofar as algedonic sensations and moods are mental but not intentional.

Brentano does address the narrowness worry, at least insofar as algedonic sensations are concerned. He argues that pain and pleasure experiences present sui generis secondary qualities, that is, secondary qualities distinct from color, sound, and the like perceptible properties. He writes: 
[When we] say that our foot or our hand hurts, that there is pain (es schmerze) in this or that part of the body ... there is in us not only the idea of a definite spatial location but also a particular sensory quality analogous to color, sound, and other so-called sensory qualities, which is a physical phenomenon and which must be clearly distinguished from the accompanying feeling. (Brentano 1874: 83 [I, 116])

For some perceptual modalities, ordinary language generously provides two terms, one naturally applicable to the experience and one to its object. Taste is a property of gustatory experiences, flavor a property of gustatory objects; smell is a property of olfactory experiences, odor a property of olfactory objects; and so on. Unfortunately, 'pleasure' and 'pain' are ambiguously applicable to both experience and object, and this is what misleads us into non-intentional thinking in this case. ${ }^{14}$

Brentano does not address the breadth worry. To my knowledge, he nowhere discusses the fact - hard to deny - that words and paintings can be directed toward objects other than themselves, even in the absence of the target objects (thus exhibiting intentional inexistence). It is reasonable to surmise, however, that he supposes they do so only by courtesy of certain mental states. The idea, familiar from modern philosophy of language, is that words and paintings have merely derivative intentionality, which they inherit from mental states. ${ }^{15}$ In this they have an intentionality crucially different from (and so to speak inferior to) mental states. Regardless, we may say that in the Brentanian picture of mentality, uninherited, nonderivative intentionality is the underlying nature of the mental. This formulation of the thesis no longer faces an immediate narrowness worry.

\section{Inner-Perceivability as Reference-Fixer}

If intentionality is the underlying nature of the mental, what is the role of innerperceivability in the concept of mind? The goal of this section is to argue that Brentano assigns something like a reference-fixing role to inner-perceivability, or more accurately to inner-perceived-ness. After elucidating Brentano's notion of inner perception and considering his case for taking it to be a central mark of the 
mental (§4.1), I develop some Brentanian ideas that suggest the reference-fixing role $(\$ 4.2)$.

\subsection{Inner Perception as a Mark of the Mental}

To the modern reader, it might seem that what Brentano calls inner perception is just what we today call introspection. But in fact Brentano explicitly distinguishes inner perception (Wahrnehmung) and introspection, which he identifies with 'inner observation' (Beobachtung). This is important, because for Brentano inner perception is the cornerstone of psychological inquiry whereas appeal to introspection is illegitimate.

To appreciate the difference between the two, consider Brentano's argument against the legitimacy of appeal to introspection:

...inner perception and not introspection, i.e. inner observation, constitutes [the] primary source of psychology.... In observation, we direct our full attention to a phenomenon in order to apprehend it accurately. But with objects of inner perception this is absolutely impossible. This is especially clear with regard to certain mental phenomena such as anger. If someone is in a state in which he wants to observe his own anger raging within him, the anger must already be somewhat diminished, and so his original object of observation would have disappeared. (1874: 29-30 [I, 40-1])

It is a central aspect of the phenomenology of anger that one is consumed by one's anger. If the subject has the presence of mind to attend to her anger, to reflect on it, she is no longer consumed by it. She has managed to 'take some distance' from it. Thus in trying introspecting one's experience, one actually exits the state one wished to introspect.

It is not my concern here to evaluate this argument; rather, I want to use it to clarify Brentano's notion of inner perception. What creates the problem for inner observation (introspection), according to the argument, is its attentive nature. It is part of the very notion of introspection, for Brentano, that the exercise of introspection involves the control and guidance of attention. ('In observation, we 
direct our full attention to a phenomenon in order to apprehend it accurately.') The problem is that attending to a conscious experience alters its intensity (if nothing else). The attentiveness of introspection implies further properties, such as voluntariness. Normally, we can decide to introspect, and equally, we can decide not to introspect, or to stop introspecting. By and large, attending, and hence introspecting, are up to us. Accordingly, introspecting is not ubiquitous: sometimes we introspect, sometimes we do not.

From the fact that Brentano's argument is not supposed to apply to inner perception, we may now infer that inner perception differs on these scores: it is nonattentive, involuntary, and ubiquitous. When one undergoes an experience of consuming anger, one is aware of it, but aware of it (i) nonattentively, insofar as one attends rather to the angering stimulus, and (ii) involuntarily, insofar as one cannot stop being aware of one's anger at will. This nonattentive, involuntary awareness is ubiquitous in our waking life. It is this kind of awareness that M4 claims is coextensive with mentality. Note, now, that M4 can be factorized into two claims:

(M4a) Only mental states can be inner-perceived.

(M4b) All mental states can be inner-perceived.

How plausible are M4a and M4b?

It might be thought obvious that only mental states can be inner-perceived. For if nonmental states could as well, what would make their perception 'inner'? However, if inner perception is by definition perception of mental phenomena, the claim that only mental states are inner-perceived is tautological. For this precise reason, Brentano offers a different, independent account of what makes inner perception inner, namely, 'its immediate, infallible (untrügliche) self-evidence (Evidenz)' (1874: 91 [I, 128]). This is what Brentano calls Evidenz, which he claims only inner perception exhibits. The substantial claim behind M4a is therefore that only mental states can be perceived with Evidenz. 
The nature of Evidenz is developed more fully and subtly in later writings (see especially Brentano 1930). The essential point, however, is that whereas in outer perception there is a causal link between the perceived and the perceiving, in inner perception the link is constitutive. Thus for an experience $\mathrm{E}$ of a subject $\mathrm{S}$ to have phenomenal property $\mathrm{P}$ just is for $\mathrm{S}$ to inner-perceive $\mathrm{E}$ as $\mathrm{P}$.

Consider the well-known fraternity initiation case. As part of his fraternity initiation, $\mathrm{S}$ is blindfolded and told that he will be cut with a razor on the lower right side of his neck. At the moment when $S$ is supposed to be cut, the presiding officials instead place an ice cube on the relevant spot. Oddly, this story is often cited in the context of attempting to undermine self-knowledge. The idea is that $\mathrm{S}$ believes that he is in pain when in fact he is not. But arguably the immediate and untutored intuition is that S's sensation, although not involving any tissue damage characteristic of pain, is still experienced as pain, that is, is a pain experience, at least in the first split second. One natural account of this is that, influenced by background expectations, S's inner perception presented S's concurrent experience as painful, and the experience's phenomenal character is constitutively determined by this presentation: for $\mathrm{E}$ to be a pain experience just is for $\mathrm{S}$ to inner-perceive $\mathrm{E}$ as painful.

By contrast, even when an external object $\mathrm{O}$ is both $\mathrm{P}$ and outer-perceived to be $\mathrm{P}$, it is not because it is outer-perceived to be $\mathrm{P}$ that it is $\mathrm{P}$; the link is merely causal and contingent. A table's characteristics are not constitutively determined by how it is (outer-)perceived. This is true even of the table's secondary qualities (e.g., its color). For even secondary qualities it is possible to misperceive: if an elephant who looks gray to the normal subject in normal conditions looks pink to me right now, then I am misperceiving the elephant's color. ${ }^{16}$ Thus only mental phenomena are such that how they are is constitutively determined by how they are (innerJperceived. In other words, only they can be perceived with Evidenz. This is M4a.

What about M4b, the claim that all mental states can be inner-perceived? In fact, according to Brentano every mental state not only can but is inner-perceived: 
Everything psychical falls under inner perception. But this does not mean that everything is noticed [i.e., inner-observed/introspected]. It is implicitly but not explicitly presented and perceived. (1982: 129 [121]) ${ }^{17}$

This extraordinarily strong claim falls out of two other aspects of Brentano's picture of mind. The first is his account of consciousness, which implies that every conscious experience is inner-perceived. The second is his doctrine that all mental states are conscious.

Brentano's account of consciousness is part of a tradition going from Aristotle (see Caston 2002) to current-day self-representational theories, which often explicitly present themselves as Brentanian (Kriegel 2003, Textor 2006, Williford 2006). According to such theories, whatever else a conscious experience may represent, it always also represents itself - indeed, it is in virtue of representing itself that it is conscious. Such theories resemble more familiar higher-order thought and higher-order perception theories of consciousness (see Rosenthal 1990 and Lycan 1990 respectively) in asserting that every conscious state is a state the subject is aware of. They differ in insisting that the conscious state and the awareness of it are the selfsame state. There is no division between a first-order conscious experience and a numerically distinct higher-order state of awareness of it. Instead, every conscious experience plays double duty as awareness of the world and awareness of itself. This is clearly Brentano's own view: one section in the Psychology is entitled 'A presentation and the presentation of that presentation are given in one and the same act.'18

Importantly for our present purposes, the relevant awareness-of-experience is inner perception. Thus another section of the Psychology is entitled 'Every [conscious] act is perceived inwardly (innerlich wahrgenommen).' ${ }^{\prime 19}$ Somewhat confusingly to the modern reader, Brentano often describes this aspect of the awareness as a cognition (Erkenntnis) or even a judgment (Urteil). But this is simply because he takes perception to be a kind of judgment, as we saw in §3.1. This supposition is particularly transparent in passages such as this: 
A double inner awareness (Bewusstein) is thus bound with every [conscious] act, a presentation which refers to it and a judgment which refers to it, the so-called inner perception, which is an immediate, self-evident cognition of the act. (1874: 143 [I, 203])

Here 'judgment,' 'perception,' and 'cognition' all refer to the same phenomenon. This is sensible against the background of the view that perception is a kind of judgment/cognition (because it presents what it does as true or real). It seems, then, that for Brentano it is in the very nature of consciousness to involve inner perception - that is, nonattentive and involuntary quasi-perceptual awareness - of the conscious experience.

The Brentanian view of consciousness is of course controversial. At the same time, many current-day philosophers think that it is quite plausible or at least viable. By contrast, Brentano's claim that all mental states are conscious would find few if any supporters in modern philosophy of mind. Yet this claim is indispensable for the plausibility of M4b. In the remainder of this subsection, I discuss this aspect of Brentano's case for M4b.

Three types of unconscious can be recognized in the modern picture of mind. First, there are sub-personal states and processes posited in cognitive-scientific explanations of behaviors manifested under experimental conditions; examples include Marr's (1982) 2.5D sketches and Milner and Goodale's (1995) dorsal-stream visual representations. Secondly, there are dispositional and tacit states posited in folk-psychological explanations of ordinary behavior - for example, the belief that the sun will rise tomorrow or the desire to be happy. Thirdly, there are Freudian subconscious states posited in 'deep-psychological' explanations of behaviors manifested in conditions of suppression, denial, and so on (e.g., Oedipal desire to kill one's father). Brentano denies that there are unconscious mental states of any of these types. He touches explicitly only on the sub-personal case, but some of the considerations he raises could be used for the dispositional and Freudian cases as well. ${ }^{20}$ 
There are several cases of sub-personal processes and states that Brentano considers, including the idea of unconscious inductive inferences supporting basic beliefs, such as that there is an external world (1874: 111 [I, 156]); hidden processes 'spitting up' spontaneous thoughts or ideas, such as a random mental image of an elephant (112 [156-7]); processes guiding appropriate absent-minded or autopilot behaviors, such as washing the dishes (113 [157-8]); and processes controlling slowly growing emotions, such as affection toward a new colleague (115 [161]). For all these cases, Brentano argues that there are other, superior explanations of the data that do not require positing unconscious mental states. In some cases (e.g., the first), the superior explanation is that certain unconscious associative processes, rather than inferential ones, are producing the relevant behavior. Thus, certain conscious experiences of cats disappearing and reappearing occur with a certain pattern, and associative processes, neurophysiological rather than properly mental, then lead to the occurrence of a conscious belief that cats persist mind-independently (1874: 111 [I, 156]). In other cases (e.g., the last), the superior explanation is that although the subject is not attentively aware of the relevant processes, she nonetheless enjoys peripheral inner perception of them. Thus, as one interacts with one's new colleague, one is ever so subtly aware here and there of being charmed by certain acts or impressed by certain remarks, and ultimately an affection grows of which one is more fully and attentively aware (1874: 116 [I, 162]).

Brentano nowhere discusses dispositional or standing states. But he does discuss apparently mental dispositions such as character traits and behavioral habits (1874: $60[1,86])$. It is natural to take these to be nonconscious mental phenomena. One might respond by denying the reality of such dispositions, but Brentano prefers a different route: acknowledge their existence and deny their mentality. This may be supported by the thought that a 'dispositional belief' is something of a rubber duck: it is disposition to believe rather than a belief proper. ${ }^{21}$ A disposition to believe is not a mental state; it is only a disposition to be in a mental state. 
Brentano does not discuss any Freudian cases either, and in 1874 he was probably unaware of them as potential counterexamples. However, the combination of the above considerations could be extended to handle them as well. One could maintain that even when a person is not fully (attentively) aware of her suppressed resentment toward her sibling, at certain times she has a dim, peripheral awareness of this resentment and at other times she does not have resentment at all but only a disposition for resentment.

This Brentanian (shall we say) case against unconscious mentality is far from frivolous. Still, it faces extraordinary difficulties. Consider visual representations in the dorsal stream, which are by and large inaccessible to consciousness, but control on-the-fly visually guided behavior. In virtue of controlling behavior on the basis of tracking environmental conditions, it is natural to consider such states mental. Certainly they appear to fall within the province of cognitive science. But Brentano would have to insist that they do not. He would also have to insist that a man engrossed in washing his car does not want to be happy (but is only disposed to want to be happy), which flies in the face of commonsense and may involve changing the meaning of 'wants.' Likewise, Brentano would also have to say that a person completely unaware of any resentment toward her sister, but consistently acting in a variety of inappropriately aggressive ways toward her, does not actually resent her sister (but is only disposed to resent her). Again this is highly counterintuitive.

The Brentanian case against unconscious mentality is thus quite problematic. At the end of the day, it is rather implausible that all mental states are conscious. To that extent, it is also implausible that all mental states are inner-perceived. Furthermore, Brentano is evidently open to the conceptual possibility that some mental states are not conscious, hence not inner-perceived. He expressly denies that the issue of unconscious mentality can be settled on verbal grounds (1874: 102 [I, 142]), and presumably would not devote the space and energy he does to such a question. In a way, the whole raison d'être of the chapter on unconscious mentality is the conceptual possibility of such. If so, it cannot be the concept of mentality that 
dictates that mental states must be inner-perceived. But our concern here is precisely with how the concept works.

Still, some of Brentano's ideas about inner perception and mentality suggest a strong connection between them, even if they are not quite coextensive. These are ideas pertaining to the role inner perception plays in our initial grasp of the mental domain. I turn to these ideas next.

\subsection{Inner Perception and Our Fix on the Mental}

We can appreciate the relevant ideas by considering Brentano's own organization of his discussion of unconscious mentality. He starts by arguing that given the nature of consciousness, there could be no direct (inner-)perceptual evidence of unconscious mentality - for whatever is inner-perceived is conscious. The question, then, is whether there might be indirect evidence for it: certain considerations that compel us to recognize mental states of which the subject is entirely unaware. There are four kinds of potential consideration Brentano mentions in this context. The first and most important is this: there might be certain phenomena (in particular, certain features of conscious experiences) whose best causal explanation requires the postulation of unconscious mental states. ${ }^{22}$

For such abductive inference to be successful, says Brentano, it must meet some conditions - certain adequacy constraints. Most of his constraints are rather innocuous: that what serves as the explanandum in any inference to the best causal explanation be a genuinely established fact (1874: 106 [I, 148]); that this fact be genuinely explained by the postulation of unconscious mental states (Ibid. [149]); that there be no better explanation of it that does not cite unconscious mental states (109 [153]). Yet, in the course of describing aspects of one of these conditions (the second one), Brentano lays down a 'sub-condition' that is far from innocuous. Moreover, this sub-condition may well embody his deepest attitude toward the relation between mentality and inner perception. 
The sub-condition comes through most clearly in Brentano's discussion of Eduard von Hartmann's postulation of the unconscious:

[Hartmann] differs from the majority of the proponents of unconscious mental acts in that he considers these acts to be heterogeneous as compared with conscious acts, as deviating (abweichend) from them in the most essential (wesentlichen) respects. It is obvious that anyone who adheres to such a view weakens the hypothesis of unconscious mental acts from the start. (1874: 107 [I, 150])

Apparently, for Brentano the thesis that some mental states are unconscious is substantive only to the extent that the putative unconscious states sufficiently resemble (are not 'heterogeneous with') conscious mental states. Calling such states 'mental' would be arbitrary if they failed to resemble conscious states. The thesis that some mental states are unconscious would come out true only because one will have effectively changed the meaning of 'mental.' Now, Brentano does not require from unconscious mental states perfect similarity to (strict homogeneity with) conscious states, and is willing to tolerate partial similarity (or 'analogy'):

... the alleged unconscious phenomena are considered, if not homogeneous with conscious phenomena, at least analogous to them to a certain extent (otherwise it would be wrong to classify them as mental activities). (1874: 108 [I, 151])

Clearly, however, some sufficient degree of similarity to conscious states is required in order for a state to qualify as mental.

Upon reflection, this is a reasonable requirement. We have many unconscious biochemical states that we are in no way tempted to call mental. Why? Brentano's answer is: because they do not resemble sufficiently conscious states. At the same time, some biochemical brain states we are inclined to treat as mental (e.g., states of the dorsal visual cortex). The reason for this, a Brentanian could say, is that they resemble conscious states in essential respects, notably insofar as they guide behavior in virtue of representing the ambient environment. As it happens, Brentano himself thinks that no unconscious states do resemble conscious states sufficiently to qualify as mental, so there are no actual unconscious mental states. 
But the concept of the mental does allow for unconscious mental states, provided they resemble sufficiently conscious states.

One way to make sense of the requirement that unconscious mental states resemble conscious ones is by thinking of Brentano as taking conscious states to constitute the prototypical or paradigmatic mental states. As noted, he is open to the conceptual possibility of unconscious mental states. But for him, it would be arbitrary to call a state 'mental' if it did not sufficiently resemble paradigmatic mental states. On this interpretation, Brentano takes the concept of mind to be a prototype concept (akin to the concept of furniture) rather than the kind of 'flat' concept that admits of definition by necessary and sufficient conditions (such as the concept of bachelor). And he takes the prototypes of mentality to be conscious states. Just as an object qualifies as furniture just if it sufficiently resembles tables and chairs (Rosch 1975), a biochemical brain state qualifies as mental just if it sufficiently resembles conscious experiences (Horgan and Kriegel 2008).

This interpretation makes sense of the passages just quoted, but does require us to attribute to Brentano a prototype conception of concepts. In addition, it also makes nonsense of Brentano's dogged search for a mark of the mental. Mark theses have the form 'All and only Fs are Gs,' so they do offer necessary and sufficient conditions for mentality.

A better interpretation, I think, is that the special status Brentano gives to conscious states in the concept MENTAL is a sort of epistemic counterpart of prototypicality. The idea is that we construct our concept of the mental on the basis of encounter with conscious experiences. Among all the items (objects, states, events, etc.) $S$ encounters in her ongoing interaction with reality are also $S$ 's own conscious experiences. This encounter with conscious experiences occurs perforce through inner perception. Noticing the similarity (or 'homogeneity') among these inner-perceived items, S spontaneously constructs a 'mental category,' or concept, that effectively collects under it anything that 'belongs together' with (is sufficiently similar to) these inner-perceived experiences. Thus the experiences that $\mathrm{S}$ 
encounters through inner perception serve to epistemically ground, or anchor, her conception of the mental. Anchoring, in this sense, is the epistemic counterpart of prototypicality. An anchoring instance is not metaphysically special - it is not more of an instance of the relevant property than other instances. But it is epistemically special - it anchors the formation or acquisition of the relevant concept (see Kriegel 2011 Ch.1). We may say that for Bretano conscious experiences, even if not prototypical instances of mentality, are nonetheless anchoring instances of MENTALITY.

Anchoring instances are epistemically prior to other instances, but are not metaphysically prior. They are not better instances. They do not have a constitutive role in making something an F. However, they do fix the reference of the F-concept. Consider the standard Kripkean model of reference-fixing (or a toy version thereof). My use of 'Napoleon' refers to Napoleon because of the conspiracy of two mechanisms: (i) a reference-fixing mechanism and (ii) a reference-borrowing mechanism. The reference-fixing occurs when, at Napoleon's proverbial baptism, his parents say 'the babe we are currently perceptually aware of shall be named Napoleon.' The reference-borrowing occurs when, much later, I use the name 'Napoleon' with the tacit intention of referring to the same thing they did (that is, to something with the same individual essence). There are various complications when we move to a natural kind term such as 'water,' but we may still imagine a twophase mechanism. Reference is initially fixed when we say or think 'the clear drinkable liquid of our perceptual acquaintance shall be known as water,' and is later borrowed when we use 'water' with the tacit intention of referring to the same stuff (that is, stuff of the same underlying nature). Likewise for the concept MENTAL: reference is initially fixed when one says 'the phenomena of my inner-perceptual acquaintance shall be called mental'; it is borrowed when one deploys the concept later with the intention of referring to the same kind of states (that is, states with the same underlying nature).

On this way of looking at things, an unconscious state would qualify as mental if it sufficiently resembled the anchoring instances that fix the reference of 
MENTAL, that is, if it had the same underlying nature as the conscious experiences inner-perceived in the process of the concept's formation. Having qualified as mental, this state would be as mental as the anchoring instances; it would not be a 'lesser instance' of mentality. This is why it makes sense to search for a mark of the mental. Our initial fix on what counts as mental is based on inner perception of conscious states, but it is nonetheless conceptually possible for mental states to be unconscious - provided they sufficiently resemble the conscious states innerperceived as the concept forms.

This casts our concept of the mental as the concept of something which has the same underlying nature as the phenomena of our inner-perceptual acquaintance. For something to qualify as mental, it must have the same underlying nature as the anchoring instances of mentality, which are all conscious states. Now, since Brentano takes intentionality to be the underlying nature of inner-perceived states, in practice unconscious states would have to exhibit intentionality to qualify as mental. To that extent, our concept of the mental picks out anything that has intentionality.

Brentano happens to think that no unconscious states do exhibit intentionality. So for him, no unconscious state qualifies as mental. But this least convincing part of Brentano's picture is rather easily excised. A Brentanian philosopher could hold that unconscious states sometimes do exhibit intentionality, and therefore do qualify as mental. For example, she may hold that states of the dorsal stream of visual cortex, although largely inaccessible to consciousness, are intentional insofar as they can sometimes misrepresent nonexistent objects. Such a Brentanian philosopher would conceive of the concept of mind just as Brentano did, disagreeing only on the concept's extension.

Interestingly, then, a Brentanian could end up assigning more or less the same extension to the concept of mind as today's mainstream philosopher of mind tends to. However, the grounds on which the two do so would still be importantly different. In current-day mainstream philosophy of mind, a state is typically taken to 
qualify as mental when it plays the right role in explaining behavior. In Brentanian philosophy of mind, it is taken to qualify as mental when it has the same underlying nature as conscious states of one's inner-perceptual acquaintance. (Arguably, underlying this difference is a much deeper gulf between the two traditions: the former takes a third-person perspective on the concept and nature of mentality, whereas Brentano takes an unapologetically first-person perspective.)

\section{Conclusion}

In summary, I have offered an interpretation of Brentano's concept of mind according to which our initial grasp or fix on the mental is based on innerperceptual encounter with conscious experiences. Other items qualify as mental just if they sufficiently resemble these inner-perceived conscious experiences in respect of underlying nature. More precisely, a subject S's state qualifies as mental iff it has the same underlying nature as phenomena of S's inner-perceptual acquaintance. As it happens, the underlying nature of these inner-perceived phenomena, and hence all mental states, is (nonderivative) intentionality: this is the feature that both demarcates the mental domain and provides its principle of speciation. So ultimately, S's state qualifies as mental iff it is intentional.

Thus interpreted, Brentano's concept of mind has crucial similarities, as well as crucial dissimilarities, to the concept dominant in modern philosophy of mind and cognitive science. The most important similarity is that it is construed as a natural-kind concept that picks out whatever has the right underlying nature, and does so via a reference-fixing description. The most important dissimilarity is that while the modern concept's reference-fixing is grounded in the explanation of behavior, Brentano's is grounded in inner perception of conscious experiences. My own view is that the Brentanian concept is much more faithful to the folk's spontaneous, natural conception of mentality (Kriegel 2011 Ch.1); but that is not part of what I have argued here. My goal here has been to bring out the structure of Brentano's concept(ion) of mind, as the concept of whatever has the same 
underlying nature as conscious experiences inner-perceived during the concept's formation, which nature happens to be intentionality. ${ }^{23}$

\section{References}

- Audi, R. 1994. 'Dispositional Beliefs and Dispositions to Believe.' Noûs 28: 419-434.

- Brentano, F.C. 1874. Psychology from Empirical Standpoint. Edited by O. Kraus. English edition L.L. McAlister. Translated by A.C. Rancurello, D.B. Terrell, and L.L. McAlister. London: Routledge and Kegan Paul, 1973.

- Brentano, F.C. 1930. The True and the Evident. Ed. O. Kraus. Trans. R.M. Chisholm, I. Politzer, and K. Fischer. London: Routledge, 1966.

- Brentano, F.C. 1982. Descriptive Psychology. Edited by R.M. Chisholm and W. Baumgartner. Translated by B. Müller. London: Routledge, 1995.

- Caston, V. 2002. 'Aristotle on Consciousness.' Mind 111: 751-815.

- Chisholm, R. 1957. Perceiving: A Philosophical Study. Ithaca: Cornell UP.

- Crane, T. 1998. 'Intentionality as the Mark of the Mental.' In A. O'Hear (ed.), Contemporary Issues in Philosophy of Mind. Cambridge: Cambridge University Press.

- Frege, G. 1892. 'On Sense and Reference.' Reprinted in P. Geach and M. Black (eds.), Translations from the Philosophical Writings of Gottlob Frege. Oxford: Blackwell, 1960.

- Horgan, T. and U. Kriegel 2008. 'Phenomenal Intentionality Meets the Extended Mind.' Monist 91: 347-373.

- Kim, C.T. 1978. 'Brentano on the Unity of Mental Phenomena.' Philosophy and Phenomenological Research 39: 199-207.

- Kriegel, U. 2003. 'Consciousness as Intransitive Self-Consciousness: Two Views and an Argument.' Canadian Journal of Philosophy 33: 103-132.

- Kriegel, U. 2011. The Sources of Intentionality. Oxford and New York: Oxford University Press.

- Kriegel, U. and K.W. Williford 2006. Self-Representational Approaches to Consciousness. Cambridge MA: MIT Press.

- Kripke, S. 1972. 'Naming and Necessity.' In D. Davidson and G. Harman (eds.), Semantics of Natural Language. Dordrecht: Reidel.

- Lycan, W.G. 1990. 'Consciousness as Internal Monitoring.' Philosophical Perspectives 9: 1-14.

- McGinn, C. 2012. Truth by Analysis. Oxford and New York: Oxford University Press.

- Marr, D. 1982. Vision. San Francisco: WH Freeman Publishers. 
- Milner, A.D. and M.A. Goodale 1995. The Visual Brain in Action. Oxford: Oxford University Press.

- Rosch, E.H. 1975. 'Cognitive Representations of Semantic Categories.' Journal of Experimental Psychology 104: 192-233.

- Rosenthal, D.M. 1990. 'A Theory of Consciousness.' ZiF Technical Report 40, Bielfield, Germany. Reprinted in N.J. Block, O. Flanagan, and G. Guzeldere (eds.), The Nature of Consciousness. Cambridge MA: MIT Press, 1997.

- Rutte, H. 1987. 'The Problem of Inner Perception.' Topoi 6: 19-23.

- Schiffer, S. 1982. 'Intention Based Semantics.' Notre Dame Journal of Formal Logic 23: 119-159.

- Seager, W. 1999. Theories of Consciousness. London: Routledge.

- Sider, T. 2011. Writing the Book of the World. Oxford: Oxford University Press.

- Textor, M. 2006. 'Brentano (and some Neo-Brentanians) on Inner Consciousness.' Dialectica 60: 411-432.

- Twardowski, K. 1894. On the Content and Object of Presentations. Trans. R. Grossmann. The Hague: Martinus Nijhoff, 1977.

- Williford, K.W. 2006. 'The Self-Representational Structure of Consciousness.' In Kriegel and Williford 2006.

${ }^{1}$ Following Chisholm (1957), the notion of intentionality is often unpacked in terms of certain failures of inference ('intensionality-with-an-s'). Two stand out: failure of existential generalization and substitution failure. Brentano himself, however, focused exclusively on failure of existential generalization; substitution failure would not assume central place until Frege (1892) and Twardowski (1894).

2 This is virtually the title of $\S 3$ of the relevant chapter of the Psychology.

${ }^{3}$ This is discussed in $\S 4$ of the demarcation chapter, though Brentano is more tentative here than with the other marks he mentions. His reservations about it are two: that it is a purely negative characterization, and that it is quite controversial (whereas a mark should be agreed upon). Still, Brentano does seem to think that this mark is just as extensionally adequate as the others; it is just that he thinks it is instrumentally problematic, for the community of inquiry, to adopt a mark whose extensional adequacy not everybody appreciates.

4 'Another characteristic which all mental phenomena have in common is the fact that they are only perceived in inner consciousness, while in the case of physical phenomena only external perception is possible' (1874: $91[1,128])$.

${ }^{5}$ This is an offshoot of the previous mark, and is discussed by Brentano in the same section. It is important to note here that the German term for 'perception' is Wahrnehmung, literally something like 'truth-taking.' Thus the German verb is even more clearly a success verb than the English. With this in mind, and given Brentano's Kantian proclivities about the object of sense perception, passages such as the following make much sense: 'Moreover, inner perception is... really the only perception in 
the strict sense of the word. As we have seen, the phenomena of the so-called external perception cannot be proved true and real even by means of indirect demonstration. For this reason, anyone who in good faith has taken them for what they seem to be is being misled... Therefore, strictly speaking, so-called external perception is not perception. Mental phenomena, therefore, may be described as the only phenomena of which perception in the strict sense of the word is possible.' (1874: 91 [I, 128-9])

${ }^{6}$ According to Brentano, all external phenomena are such in the Kantian sense of being appearances. The only phenomena that have 'noumenal reality' are the self and its modifications. Here no gap between appearance and reality is possible. Accordingly, mental appearances are also mental realities, whereas physical appearances are not also physical realities. An argument along these lines can be found already in pp. 9-10 of the Psychology, and is repeated in $§ 7$ of the demarcation chapter.

${ }^{7}$ Brentano writes: 'We can say [that] insofar as the whole multiplicity of mental phenomena which appear to us in our inner perception always appear as a unity, which the same is not true of the physical phenomena which we grasp simultaneously through the so-called external perception.' (1874: 96 [I, 135]) This discussion presupposes a fairly involved mereological conception of unities as special kinds of wholes or sums, a conception developed more fully by Brentano on a completely different occasion (see Brentano 1982).

${ }^{8}$ The intentional mark is not even discussed at greater length than all of the others. In the English edition, three pages are dedicated to it in the demarcation chapter. By contrast, the 'presentation' mark is discussed over five pages and the 'extension' and 'unity' marks take three pages each as well.

${ }^{9}$ The metaphysics of matter raises a number of questions singular to it, which have been treated in an independent manner at least since Aristotle (e.g., the problem of the statue and the clay, now discussed under the heading of 'material constitution'). Meanwhile, the metaphysics of mind, and in particular its relation to matter, have been the topic of dedicated discussions around the 'mind-body problem.' And problems about the status of abstracta - from universals through numbers to values have likewise been the topic of dedicated discussions.

10 The idea that the origin of the three-way distinction between the physical, the mental, and the abstract is sometimes presented in a deflationary spirit, that is, in the context of voicing skepticism about there being a real distinction between the three. Thus, McGinn (2012 Ch.11) argues that 'ontology rests on a mistake,' as they say, inasmuch as it rests on an illicit inference from an epistemic to a metaphysical tripartite division of putative entities. However, this deflationary take is not built into the idea itself.

11 More precisely, there is here a sui generis kind of directedness at the good. One can of course believe that the espresso is good, but such a belief does not qualify as a state of interest by Brentano's light. Brentano flags sensitivity to this point by writing: 'I do not believe that anyone will understand me to mean that phenomena belonging to this class are cognitive acts by which we perceive the goodness or badness, value or disvalue of certain objects. Still, in order to make such an interpretation absolutely impossible, I explicitly note that this would be a complete misunderstanding of my real meaning.' (1874: 239 [II, 89]) It seems that Brentano has in mind a distinctively conative way of being directed at the good.

${ }^{12}$ Presentation is, for Brentano, the most basic type of mental phenomenon, as judgment and interest always presuppose a presentation. Accordingly, in Brentano's own expositions of the three classes presentation tends to be the first. 
${ }^{13}$ Kripke would put this by saying that the thesis that intentionality is the essence of the mental is necessary a posteriori. Brentano does not tend to make modal claims, so he would not put it this way. Still, the commonality with the Kripkean notion of underlying nature is evident.

${ }^{14}$ I am not familiar with a discussion of moods in Brentano. However, there are standard intentional treatments of moods, most notably the view that moods present properties of the world as a whole. 'Being depressed is a way of being conscious of things in general: everything seems worthless, or pointless, dull and profitless,' as Seager (1999: 183) writes (see also Crane 1998).

15 The view is a central tenet of Gricean intention-based semantics (e.g., Schiffer 1982), but seems to be shared more widely.

16 It is true that with secondary qualities, there is a kind of global error that is likely impossible; but local errors are still possible. Things are different with inner perception: according to Brentano, here even local misperception is impossible.

17 This is from a lecture series on inner perception from 1887-8, reprinted in English translation in Brentano 1982.

18 This is $§ 8$ of Book II, Chapter 2. In it Brentano writes: '... inner experience seems to prove undeniably that the presentation of the sound is connected with the presentation of the presentation of the sound in such a peculiarly intimate way that its very existence constitutes an intrinsic prerequisite for the existence of this presentation. This suggests that there is a special connection between the object of inner presentation and the presentation itself, and that both belong to one and the same mental act.' (1874: 127 [I, 179])

19 This is $§ 4$ of Book II, Chapter 3. I have changed Brentano's 'mental' to 'conscious' because, while in his discussion he has already shown that the mental and the conscious are coextensive, here this remains to be discussed.

20 Brentano's own discussion - in Bk I Ch.3 $§ 6$ and Bk II Ch.2 esp. §4 - is not organized around these three alleged types of unconscious.

21 To posit dispositional beliefs on top of dispositions to believe would seem to be explanatorily pointless. Thus dispositional beliefs, insofar as they are meant to be more than just dispositions to believe, would appear to be explanatorily preempted by the latter (see Audi 1994).

22 One apparent blindspot in Brentano's discussion is his lack of consideration of behavioral phenomena whose best causal explanation might call for the postulation of unconscious mental states. He virtually only considers conscious phenomena that might call for such postulation.

23 This work was supported by the French National Research Agency's ANR-11-0001-02 PSL* and ANR-10-LABX-0087. For comments on a previous draft, I am grateful to Arnaud Dewalque, Guillaume Fréchette, and Denis Seron. I have also benefited from presenting the paper at conferences at the McMaster University and University of Salzburg; I am indebted to the audience there, in particular Johannes Brandl, Arkadiusz Chrudzimski, Daniel Harris, Colin Johnson, Sonia Kamińska, Sandra Lapointe, Olivier Massin, Dan Shargel, Ion Tanasescu, Mark Textor, Genki Uemura, and Alberto Voltolini. 